\title{
Characterizing consumer emotional response to sweeteners using an emotion terminology questionnaire and facial expression analysis
}

K.A. Leitch ${ }^{\text {a }}$, S.E. Duncan ${ }^{\mathrm{a}^{*}}$, S. O'Keefe ${ }^{\mathrm{a}}$, R. Rudd ${ }^{\mathrm{b}}$, D.L. Gallagher ${ }^{\mathrm{c}}$

${ }^{a}$ Department of Food Science and Technology, Virginia Polytechnic Institute and State University, Blacksburg, VA 24061, USA

${ }^{\mathrm{b}}$ Department of Agriculture and Extension Education, Virginia Polytechnic Institute and State 12 University, Blacksburg, VA 24061, USA

${ }^{\mathrm{c}}$ Department of Civil and Environmental Engineering, Virginia Polytechnic Institute and State University, Blacksburg, VA 24061, USA

*Corresponding author: $\quad$ Tel: $\quad+1$ 540-231-6806; Fax: +1 540-231-9293 


\section{Abstract}

Concerns associated with sugar-sweetened beverages (SSBs) have led to an increased consumer demand for sweetener alternatives that are functionally (and taste) equivalent to

36 sucrose without the associated health risks. Measuring consumer emotions has the potential to

37 aid the industry in subsequent ingredient decision-making. The purpose of this study was to

38 evaluate the relationship of consumer acceptability and emotional response of sweeteners in tea

39 using a 9-point hedonic scale, an emotion term questionnaire (explicit), and a facial expression

40 response (implicit).

41 Participants $(\mathrm{n}=30)$ evaluated a water sample (baseline), two (5\%) sucrose-tea samples

42 (control), and four equi-sweet alternative sweetener-tea samples (ace-k, sucralose, high fructose

43 corn syrup and honey), divided by category (artificial; natural). Sessions (4 total, spread over 2

44 days) were divided by category and emotional response tool in a cross-over design. Facial

45 expression responses were recorded in the first session of both days using FaceReader 5.0 and

46 individual participant videos were analyzed per sample for 5-sec post-consumption $(\alpha=0.05)$ in

47 the continuous analysis setting using automated facial expression analysis software. Emotional

48 term responses were collected in the second session of each day and count frequencies of each

49 term per sample were tabulated and analyzed. Hedonic acceptability was rated in all sessions on

50 a 9-point scale.

51 Alternative sweeteners were all rated 'acceptable' (score of 5 or higher), except for honey

52 in one session. Only one alternative in each category was statistically different $(\mathrm{p}<0.05)$ in liking

53 from sucrose. Facial analysis showed minimal differences in emotion elicited across sweetener

54 categories. Time series analysis was more robust in showing differences $(\mathrm{p}<0.05)$ than baseline

55 comparisons. Emotional term selection using a CATA questionnaire showed four unique terms 
56 (disgusted, good, mild, steady) for natural sweeteners and two unique terms (bored, good-

57 natured) for artificial sweeteners. More research exploration related to emotions and food is

58 needed in order to accrue a more accurate picture of consumer product preferences.

59

60 Keywords:

61 Emotion, Facial Expression Analysis, Sweetener, Consumer

62

63

64

65

66

67

68

69

70

71

72

73

74

75

76

77

78 


\section{Introduction}

Sucrose is the standard sweetener to which all other sweeteners are compared in the

81 beverage industry. This is largely attributed to its inherent sweetness, which studies have shown

82 elicit positive affective responses in humans (de Graaf \& Zandstra, 1999; Rozin \& Vollmecke,

83 1986; Steiner, Glaser, Hawilo \& Berridge, 2001), paired with its clean flavor profile, texture,

84 color, shelf-life and ubiquitous abundance in nature (Mitchell, 2006). Sucrose alternatives,

85 traditionally chosen for cost reduction and/or consumer weight control, include those readily

86 found in nature and sweeteners artificially produced in a laboratory setting (Nabors, 2012).

87 Taste, whether expected or remembered through conveyed information on packaging, is

88 one of the most important factors when making product choices (International Food Information

89 Council, 2013; Koster, 2002; Schifferstein, Fenko, Desmet, Labbe, \& Martin, 2013); however,

90 most U.S. consumers believe that sugar consumption is associated with weight gain and should

91 therefore be avoided (IFIC, 2013). The use of alternative sweeteners in beverages, consequently,

92 is advantageous for health conscious consumers. Recent consumer reports have shown that there

93 is a gap in knowledge concerning the relationship between (1) sugar intake and consumer health

94 and (2) the difference in functionalities between specific sweeteners (such as high fructose corn

95 syrup) (Cogent Research, 2006; IFIC, 2013). Evidence from peer-reviewed literature addressing

96 food-health concerns has shown that consumer beliefs heavily influence their acceptance or

97 rejection of food products and ingredients (Dickson-Spillmann, Siegrist, \& Keller, 2011; Rozin,

98 Ashmore, \& Markwith, 1996). Increasing popularity surrounding food products that are organic,

99 non-GMO, 'natural', and have "clean labels", etc. is largely attributed to the perceived and/or

100 expected health benefits of these products rather than their functionality (Devcich, Pedersen \&

101 Petrie, 2007; Rozin, Spranka, Krieger, Neuhaus, Surillo, Swerdlin, \& Wood, 2004). Thus, 
102 industry response has focused on creating products that are 'healthier' and meet the high taste

103 expectations that have been previously established in the original products.

104 Success is not solely driven by taste; consumer attitudes and perceptions of the product,

105 its ingredients and all associated branding have an effect that is often hard to quantify. The

106 challenge in sensory science lies in developing a more complete understanding of drivers of

107 consumer preferences. Consumer emotions contribute to purchase habits and, more importantly,

108 brand and product loyalty (Lindstrom, 2005). Emotions occur very quickly (microseconds) and

109 have a short duration (seconds to a few minutes) (Robbins \& Judge, 2013). Preferences for one

110 product over another are often attributed to a combination of several internal and external

111 factors. Measuring emotions evoked by food are consequently due to an exponential number of

112 confounding factors, although most recent research suggests that food related experiences are

113 often described in positive terms (Desmet \& Schifferstein, 2008; Gibson, 2006; King \&

114 Meiselman, 2010).

115 New methods exploring the role of consumer emotions and perceptions of foods include

116 collecting both explicit and implicit measures. Explicit methods rely on participant cognition of

117 and ability to recognize (emotional) response, much like traditional sensory methods already in

118 use by the industry for acceptance or preference. Limitations involving emotions research can

119 include high panelist to panelist variation, within panelist inconsistency and a lack of emotion

120 term understanding especially in the context of food liking and preferences (Booth, 1994; Köster,

121 2002). The application of methods measuring subconscious (or implicit) responses that cannot be

122 controlled, typically neurological or physiological, may augment assumptions made in explicit

123 approaches. Several studies in the psychology field show that expressed emotions can be

124 categorized as positive/negative or approach (meaning "towards stimuli") or withdrawal ("away 
125 from stimuli”). Approach emotions include angry, happy and surprised and withdrawal emotions

126 include disgusted, sad and scared based on brain asymmetry (Alves, Fukusima, \& Aznar-

127 Casanova, 2008; Davidson, Ekman, Saron, Senulis, \& Friesen, 1990). Implicit measures include

128 temperature \& sweat changes, heart rate, electroencephalography, and functional magnetic

129 resonance imaging to evaluate the relationship to food stimuli (de Wijk, Kooijman, Verhoeven,

130 Holthuysen, \& de Graaf, 2012; Hu, Player, McChesney, Dalistan, Tyner, \& Scozzafava, 1999).

131 Manual facial coding, such as Facial Action Coding System (Ekman \& Friesen, 1978), as well as

132 automated facial expression analysis (AFEA) tools (FaceReader ${ }^{\mathrm{TM}}$, PrEmo, Affdex) are less

133 invasive; however, they can be time consuming, and the software reliability and accuracy related

134 to food stimuli is not well understood. Of the very few studies using facial expression analyses

135 (Danner, Sidorkina, Joechl, \& Duerrschmid, 2013; Danner, Haindl, Joechl, \& Duerrschmid,

136 2014; De Wijk et al., 2012; Garcia-Burgos \& Zamora, 2015), most have focused solely on

137 measuring single or dominant emotions at a set time period.

138 The purpose of this project was to compare natural and artificial sweeteners to the

139 traditional standard, sucrose, for acceptability as well as implicit and explicit emotional

140 responses. The specific objective was to evaluate the relationship of consumer acceptability and

141 emotional response of sweeteners in tea using a 9-point hedonic scale, an emotion term

142 questionnaire (explicit), and a facial expression response (implicit).

\section{2. Materials and Methods}

1452.1 Samples \& sample preparation

146 Acesulfame potassium (ace-k; Wego Chemical \& Mineral Co.; Great Neck, NY), high

147 fructose corn syrup (HFCS; Tate \& Lyle; London), honey and sucrose (Kroger; Cincinnati, OH) 
148 and sucralose (Sucral; Tate \& Lyle; London) were received by donation or purchased at the local

149 supermarket. Preliminary testing established sweetness equivalence of alternative sweeteners to a

$1505 \%$ sucrose in water solution (w/w). Five sweetened tea solutions, using alternative sweeteners

151 and sucrose (control), were made approximately $24 \mathrm{hr}$ prior to each sensory testing day. Each

152 batch solution of tea (Lipton Tea, Unilever, Englewood Cliffs, NJ) was prepared based on

153 package instructions (Southern Sweet Tea, n.d.). Drinking water (Kroger brand, Cincinnati, $\mathrm{OH}$ )

154 was brought to a simmer $\left(\sim 99^{\circ} \mathrm{C}\right)$. Tea leaves $(\sim 4 \mathrm{~g})$, bundled in cheesecloth, were placed in a

155 heatproof container, heated water $(355 \mathrm{~mL} / 4 \mathrm{~g}$ tea leaves) was added to packaged tea, steeped

156 (covered) for 3-5 minutes, then tea leaves were removed. Pre-measured sweeteners were added

157 to the appropriate volume of tea (Table 1). Sweetener-tea solutions were mixed, then transferred

158 into pre-labeled $750 \mathrm{~mL}$ wine bottles, covered and stored overnight $\left(4^{\circ} \mathrm{C}\right)$. Sweetener-tea

159 solutions were poured into color-coded sample cups ( 2 oz. plastic; Solo brand) with caps prior to

160 testing.

161

1622.2 Participant recruitment \& pre-screening study

163 Virginia Tech (VT) Institutional Review Board (IRB) approval was obtained prior to

164 beginning the study. Informed consent and consent for the video recording were obtained prior to

165 data collection. Recruited panelists were screened based on consumption of tea beverages

166 (invited participants consumed tea on a weekly basis or greater), use of various sweeteners

167 (invited participants reported using either "natural" or "non-nutritive" sweeteners with

168 beverages) and facial features (facial hair, glasses) that might interfere with video capture for

169 facial expression analysis. A preliminary video trial was used to evaluate participant $(\mathrm{n}=65 ; 47$

170 females) adherence to training instructions to limit risk of failed video. All captured videos were 
171 run through the automated facial expression software program (FaceReader 5.0 ${ }^{\mathrm{TM}}$, Noldus

172 Information Technology, Wageningen, The Netherlands) and assessed for video success. Thirty-

173 one individuals (Virginia Tech students, faculty, staff and community members; age range 20-

174 60: $72 \%$ female) were invited to continue in the study.

175

176

\subsection{Experimental cross-over design}

On each testing day $(n=2)$, participants completed two sessions. Sessions were divided

178 based on sweetener category (natural; artificial) and the emotional collection tool used (video 179 capture of facial expression response, FER; emotional term selection, ETS) (Figure 1). Video

180 capture of their face occurred in the first session of the evaluation on each day. In the second 181 evaluation session, participants characterized their emotional response by selecting emotional 182 terms from a check-all-that-apply (CATA) list. In each session, participants tasted and rated 183 overall acceptability of tea-sweetener samples ( 2 artificial + sucrose; 2 natural + sucrose; 6 184 samples each day; total of 12 samples over a 2-day testing period) on a 9-point hedonic scale $(1=$ 185 dislike extremely; 5= neither like nor dislike; $9=$ like extremely). The order of natural and 186 artificial sweetener sessions was reversed on the second day.

\subsection{Experimental environment, testing sequence \& data management}

\subsubsection{Session 1: FER \& sweetener acceptance}

In order to best control and standardize FER video capture, one sensory booth was used

191 for all participants; each participant was scheduled with individual sessions. White lighting in the

192 booth and incidental lighting from overhead lights and from the booth's touch screen monitor

193 illuminated the face. A webcam (Microsoft 2.0 megapixel LifeCam NX-6000, Redmond, WA), 
194 attached to the bottom of the touch screen monitor, was positioned for each participant to best 195 capture the face; the webcam was connected to a laptop (Latitude Essio, Dell, Inc., Round Rock, 196 TX) on the researcher side of the hatch. This also allowed the researcher to provide further

197 instructions to ensure better video capture, as suggested by Arnade (2013). The webcam was 198 preset to capture 30 frames/sec with set frame dimensions (640w x 480h) while recording; video 199 recording began at the start of each testing session and captured the entire first session of each 200 testing day using Microsoft Movie Maker (2011). Videos were saved as Windows media video 201 (.wmv) files.

202 During the first testing session, the participant was seated in the booth and presented 203 simultaneously with a water sample (Drinking water, Kroger brand, Cincinnati, OH) and 3 color204 coded sweetened tea samples. While being video recorded, they first tasted the water sample in 205 order to elicit a neutral emotional response, which established a video baseline. The expectation 206 was that this preliminary water tasting would help to reduce as much "emotional" noise as 207 possible and give the researcher a standard response from each panelist. The remaining three 208 samples (two sessions per day; two days) were randomized in a balanced complete block design.

209 Panelists were not informed which sweeteners were used in each sample or the 'sweetener 210 category' used in each session. Each panelist evaluated samples under white lighting, from left to 211 right; water and unsalted soda crackers were provided to cleanse the palate between samples. 212 Panelists held up a uniquely colored index card (placed on top of each sample and coded

213 for samples specific to a category), prior to tasting, to provide a video record of the sample being 214 evaluated. Panelists were instructed to take the whole sample $(30 \mathrm{~mL})$ into their mouth, swallow 215 and sit for a "wait period" of $30 \mathrm{sec}$, which was programmed into the management software 216 (Sensory Information Management System, SIMS; version 6, Sensory Computer Systems, 
217 Berkeley Heights, NJ). This ensured that the amount of time allotted for panelists to respond

218 emotionally was the same per sample. Acceptability scores ( $1=$ dislike extremely; $5=$ neither like

219 nor dislike; 9= like extremely) were collected via touchscreen monitor and the data was stored on

220 the computer server until completion of the study at which point all responses were transferred to

221 an electronic data spreadsheet (Microsoft Excel, Microsoft Corporation, Inc., Redmond, WA) for

222 further analysis.

223 All video files were batch analyzed using the facial expression analysis software with

224 continuous face calibration setting, which is one of three (default, continuous, \& individual)

225 calibration settings (FaceReader 5.0 ${ }^{\mathrm{TM}}$, Noldus Information Technology, Wageningen, The

226 Netherlands). The goal is to reduce variation for each elicited emotion across participants. The

227 default setting utilizes an internal software library with which to base the mean intensities for

228 each emotion. In contrast, both continuous and individual settings actively eliminate participant

229 bias by applying a correction factor while running the analysis; however the individual

230 calibration requires a "baseline" image/video (minimum of 10 secs) for all participants in order

231 to remove personal bias(es). Unpublished results from our lab group suggest that the continuous

232 setting produces a higher sensitivity in determining emotional response differences than the

233 Version 5.0 software default setting and is less involved than the individual calibration setting.

234 Each recording was then event marked for a period of $5 \mathrm{sec}$ post-consumption, based on when

235 the hand holding the sample cup fell below the chin, in order to identify the relevant data for all

236 samples (including water; 8 total per panelist). Log files for each panelist were exported and

237 compiled into an electronic spreadsheet for further analysis. R code (R 3.1.1, R Core Team,

238 2014) was created to identify and extract the desired facial expression data for each sample per

239 panelist for statistical analysis. Facial expression data for water was analyzed as a 'sample' in 
240 comparison to the sweetened tea samples in each category and also as a baseline, where its post-

241 consumption mean was subtracted from the other mean samples using R.

\section{2.4.2 Session 2: ETS \& sweetener acceptance}

244 Immediately following the first session, panelists were guided into a separate room and

245 directed to a seat with a trifold board to simulate a sensory booth. Upon arrival, participants

246 completed 2 questionnaires (a demographic and beverage intake questionnaire; Hedrick,

247 Comber, Estabrooks, Savla, \& Davy, 2010), given only on the first testing day.

248 All participants were presented with one water sample and three color-coded tea-

249 sweetener samples under white florescent lighting. Samples were presented at the same time and

250 participants were asked to evaluate each color coded sample one at a time from left to right,

251 consuming water and unsalted soda crackers (Kroger brand, Cincinnati, $\mathrm{OH}$ ) between each to

252 cleanse the palate. Immediately following consumption of the sweetened tea samples, panelists

253 were directed to rate their acceptability score at the top of the modified EsSense ${ }^{\mathrm{TM}}$ paper ballot

254 (King \& Meiselman, 2010) and select all applicable emotional terms from the list of 43 provided

255 (38 of the original 39 terms used). One term (glad) was removed due to its similarity in meaning

256 to the term "happy" and five terms (angry, content, fearful, sad and safe) were added to the ballot

257 that more directly correlate to the emotions represented in the facial expression software

258 program. All panelist demographic, hedonic and emotion term data from session 2 was recorded.

2602.5 Statistical analyses

261 2.5.1 Sweetener acceptance 
Mean hedonic scores for each sweetener within both categories (natural; artificial) and

263 data collection tools (facial expression; CATA emotional term list) were calculated (Microsoft

264 Corporation, Inc., Redmond, WA). Distribution normality was tested using the Shapiro-Wilk

265 goodness-of-fit test (JMP vs 9.2, SAS, Cary, NC) for each sweetened tea sample. Nonparametric

266 one-way analyses of variances (ANOVAs) using the Kruskal-Wallis test were conducted (JMP

267 vs 9.2, SAS, Cary, NC) to determine differences $(\mathrm{p}<0.05)$ among mean hedonic scores within

268 each sweetener category for both collection methods.

269

270

\subsubsection{Facial expression response}

271 Emotion intensity means, each scaled 0-1 ( $0=$ not expressed; $1=$ fully expressed) for all

272 participants and samples, $5 \mathrm{sec}$ post-consumption, were generated from FaceReader ${ }^{\mathrm{TM}}$ output

273 using R. Repeated one-way ANOVAs were conducted within emotion state (sad, surprised,

274 happy, scared, angry, disgusted and neutral), across sweeteners (water, sucrose, HFCS, honey,

275 ace-k, and sucralose) and within sweetener, across emotions using Tukey's HSD multiple

276 comparison of means in R. Significance was determined with critical values less than 0.05 . The

277 relationship between mean facial expression intensity values of emotions and hedonic score

278 (liking) for each sweetened tea sample was evaluated using a liner regression analysis (JMP

279 SAS, Cary, NC). Coefficients of determination ( $\mathrm{R}^{2}$ values) were found and used to obtain

280 correlation values ( $\mathrm{R}$ values) within each sweetener category.

281 The time series data for each emotion were collected at 20Hz. The start times for each

282 sample were adjusted to zero, t-tests, paired by panelist, evaluated the mean difference for each

283 emotion at each time step (Spivey, Grosjean \& Knoblich, 2005) between the sweetener and water

284 over the $5 \mathrm{sec}$ interval. Signs of the mean difference (sweetener - water, data not shown) were 
285 used to evaluate whether the sweetener or water had the stronger emotional response. P-values

286 (Figures 2 and 3) were used to evaluate statistical significance $(\mathrm{p}<0.05)$ and duration of

287 emotional differences.

288

289

\subsubsection{Emotional term selection}

Count frequencies for each emotion term (43 total) were calculated for all sweeteners in

291 both categories (natural; artificial). Terms selected with $20 \%$ frequency or more for at least one 292 sweetener-tea sample were classified as "frequently selected" (Arnade, 2013); These terms were 293 graphed to compare for overall similarities and differences. "Shared" terms across sweetener 294 comparisons were identified from frequently selected terms and had less than $8 \%$ difference 295 between sample frequencies. "Unique" terms exhibited greater than $20 \%$ selection frequency for 296 one sample and greater than $10 \%$ difference in frequency between two sweeteners. Penalty-lift 297 analysis (Meyners, Castura \& Carr, 2013) and a Cochran's Q test for significance $(\alpha=0.05)$ were 298 used to assess the significance of frequently selected terms and the relationship to mean hedonic 299 scores within each sweetener category.

\section{3. Results and Discussion}

There are a number of physiological (taste) and neurological (perception/cognition,

303 emotion and memory/expectation) processes involved when capturing consumer acceptance and

304 response to food products. This creates a complex problem when measuring implicit and explicit

305 emotions. From a biological perspective, research studies have shown that nutritive and non-

306 nutritive sweeteners activate the same taste receptors (T1Rs) on the tongue (Birch, 1987; Nelson, 307 Hoon, Chandrashekar, Zhang, Ryba \& Zuker, 2001; Li, Inoue, Reed, Hugue, Puchalski, Tordoff, 
308 Ninomiya, Beauchamp, \& Bachmanov, 2001; Li, Staszewski, Xu, Durick, Zoller \& Adler, 2002).

309 While little individual variation in the ability to detect sweet taste may exist, Nie, Vigues, Hobbs,

310 Conn \& Munger (2005) showed evidence that non-nutritive sweeteners may bind to taste

311 receptors with a higher affinity than their nutritive counterparts. Neurological studies suggest

312 that the pleasantness/reward system in the brain differs across sweetener types (Frank, et al.,

313 2008) and frequency of consumption for an individual (Green \& Murphy, 2012).

314 These physiological responses, in conjunction with many social, environmental and

315 psychological factors, influence the emotional processing of food products in the brain (Cardello,

316 1994; Gibson, 2006). The characterization of individual emotional responses can differ greatly

317 depending on the type of measurement (verbal, nonverbal) used. We attempted to address these

318 differences by collecting implicit emotions through facial expression responses and cognitive

319 responses through acceptance as well as explicit emotions through a verbal check-all-that-apply

320 ballot.

3223.1 Acceptability of sweeteners in tea

323 It has been well established that imparted sweetness via sucrose or alternative sweeteners

324 is inherently acceptable and elicits positive emotions across cultures and ages (De Graaf \&

325 Zandstra, 1999; Greimel, Macht, Krumhuber, \& Ellgring, 2006; Rozin \& Vollmecke, 1986;

326 Steiner et al., 2001); water has also been shown to produce neutral emotions via facial

327 expressions (Steiner, 1979; Steiner et al., 2001). This general acceptance can be altered when

328 sweeteners are added to a more complex beverage such as black tea, which is characterized by

329 bitter flavors from the effects of nonvolatile and volatile compounds extracted from tea leaves

330 during brewing (Balentine, Wiseman, \& Bouwens, 1997). Results showed that most sweetened 
331 tea samples were well liked with acceptability scores falling between "like slightly" to "like

332 moderately." Any influence on acceptability due to the imparted bitterness from tea was assumed

333 to be consistent across all sweeteners.

334 Honey and ace-k had mean values significantly lower $(\mathrm{p}<0.05)$ than sucrose with scores

335 falling between "dislike slightly" to "neither like nor dislike" (Table 2). Lower acceptability in

336 honey was unexpected since it is among the oldest sweetening agents (White, 1978) and is

337 generally added to tea-based beverages. Data suggests that there were two participant user

338 groups (honey users and non-users); left skews were observed for all other sweetened samples in

339 both sessions. Hedonic scores for all samples were not normally distributed. Lowered

340 acceptability of ace-K was not unexpected due to its association with bitter flavor, which is

341 generally viewed as an inherently aversive taste (Fischer, Griffin, England, \& Garn, 1961; Rozin

$342 \&$ Vollmecke, 1986). We speculated that bitter flavor may have been compounded by the

343 combination of ace- $\mathrm{K}$ and tea, resulting in lowered acceptance.

344 Panelist reliability is suggested by sucrose (control) comparisons ( $\mathrm{p}>0.05)$ within and

345 across categories (natural; artificial) (Table 2). No differences ( $p>0.05$ ) existed between mean

346 scores of each alternative sweetener across the two sessions (FER; ETS), further supporting

347 panelist reliability. We concluded that any differences in liking for alternative sweeteners were

348 attributed to other factors such as sweetener flavor profile, consumer perception and/or emotions.

\subsection{Characterizing explicit emotional responses to sweeteners in tea}

352 In order to distinguish differences among those factors, frequently selected verbal

353 emotion responses were identified for each sweetener type. A similar proportion of emotion 
354 terms, approximately $40 \%$ (17-18 out of 43 terms), were classified as frequently selected in both

355 sweetener categories (natural; artificial). Reported differences across categories were

356 demonstrated when comparing the two sucrose (control) samples, which shared only six terms

357 across both sessions (Figure 2a). Three shared terms (good-natured, peaceful, pleasant) were

358 identified among the natural sweeteners. Five shared terms (content, friendly, good, pleased,

359 quiet) were identified among the three sweeteners in the artificial session. Two terms

360 differentiated honey (disgusted, $\mathrm{p}=0.002$; mild, $\mathrm{p}=0.028$ ) based on Cochran's Q test (Figure 2b).

361 In addition, based on our pre-defined category of "unique", the term good was selected more

362 frequently for HFCS and steady was selected more frequently for honey compared to sucrose;

363 the term bored was selected more for ace-k and good-natured was selected more for sucralose

364 compared to sucrose. These results further support the hedonic score data, which showed a

365 significant decrease in liking for honey in the natural category.

366 Penalty-lift results in this study showed that two terms, bored (ranging between -0.27 and

$367-1.64$ ) and mild (ranging between -0.19 and -0.81 ) had negative penalty towards hedonic scores

368 when selected for sweeteners in both categories (Figure 3). In the natural category, the negative

369 penalty was driven by sucrose and honey, respectively. One additional term, disgusted (-2.37),

370 showed a high negative penalty only for the natural category and was uniquely associated with

371 honey.

372 A majority of the terms in the natural category ( 9 out of 14 positive terms) showed

373 minimal positive mean differences, with ranges between 0 and 1 , while a majority of the terms

374 (10 out of 15 positive terms) showed higher positive differences (1-1.5 range) for the artificial

375 category (Figure 5). The highest positive differences for sweeteners were seen in the terms

376 pleased (1.22) and happy (1.20) in the natural session, and pleased (1.67) and good (1.53) in the 
377 artificial session (Figure 3). Interestingly, both pleased and happy were driven by sucrose and

378 HFCS in the natural session, as neither term was frequently selected for honey. The positive

379 penalty makes sense when comparing it to the hedonic scores of these sweeteners.

380 Previous studies investigating the relationship between product acceptability and emotion

381 scores (King \& Meiselman, 2010; Porcherot, Delplanque, Raviot-Derrien, Le Calve, Chrea,

382 Gaudreau, \& Cayeux, 2010) have conflicting results. In a study conducted by King and

383 Meiselman (2010), consumers categorized specific terms associated with the eating experience

384 into one of three groups: positive, negative or unclear. Correlations between overall liking and

385 positive or negative terms were shown; however when examining product differences,

386 acceptability and emotion score data was variable. Similar conclusions can be drawn from

387 results in this study. In general, liked sweeteners (sucrose, HFCS, sucralose) were associated

388 with neutral to positive terms, while neutrally liked to disliked sweeteners (honey and ace-k)

389 were uniquely associated with negative terms. Evidence for these conclusions were supported by

390 the Cochran's Q test as well as penalty lift results. It is interesting to note that emotion term

391 selection patterns elicited by artificially categorized sweeteners were more closely related than

392 that of their nutritive counterparts (Figure $2 b \& 2 c$ ).

393 Studies investigating the linguistic relativity theory (Whorf, 1956) have shown that the

394 ability to detect and perceive emotions within oneself can be greatly influenced by language

395 (Gendron, Lindquist, Barsalou \& Barrett, 2012; Lindquist, Barrett, Bliss-Moreau, \& Russell,

396 2006). This evidence suggests that there was potential for participant response bias due to the

397 unbalanced nature of positive (34) and negative (9) emotion terms used in the CATA ballot.

398 Furthermore, panelists were not trained in their understanding of the emotion words and could

399 have easily misinterpreted term meaning(s) or selected specific terms as way of post- 
400 rationalizing an affective experience to a sweetener. In this way, the emotional response may

401 have been misdirected due to the prompted emotional terms on the ballot. Another limitation of

402 the CATA ballot used in our study included an alphabetical order and position of terms, which

403 may increase potential for certain terms to be selected over others because of positioning in the

404 sequence (King, Meiselman, \& Carr, 2013). In addition, the CATA fomat reduces the number of

405 terms selected compared to a rating scale format (King, Meiselman, \& Carr, 2013). Testing a

406 product under different contexts may also influence emotional term profile.

\subsection{Characterizing implicit emotional responses to sweeteners in tea. It is debated} whether affect precedes cognition or vice-versa and what role emotions play in the decision 410 making process (Zajonc, 1980). ANS (automatic nervous system) responses, such as facial 411 expressions, are believed to capture subtle discrepancies in emotion that are otherwise missed 412 when participants self-report. Pleasant affective responses to stimuli have been shown to elicit 413 specific action unit facial movements (“Cheek raiser" and "lip corner puller"), which uniquely 414 correspond to "happy" (Ekman, Friesen, \& Ancoli, 1980; Kohler, et al., 2004). As such, it was 415 believed that sweeteners with higher hedonic scores would glean higher mean intensities for 416 "happy" and lower mean intensities for "disgust" with the opposite being true for disliked 417 sweeteners (ace-k and honey). No statistical ( $p>0.05)$ differences were seen within emotion across any sweetener 419 samples in their respective categories (Tables 3, 4). Repeated one-way ANOVAs within samples 420 (in each category separately) across each of the 6 emotions (sad, surprised, happy, scared, angry 421 and disgusted) and neutral state did show some statistical differences $(\mathrm{p}<0.05)$ suggesting small 422 (weak) differences in overall response. A similar intensity pattern (ordered highest to lowest) for 
423 the six basic emotions and neutral was revealed; neutral was elicited with the highest intensity,

424 followed by sad for all sweeteners. Coefficients of determination were very small and showed

425 little to no correlation between emotions and hedonic score (liking).

426 The lack of significant correlations between emotional response and hedonic score

427 (liking) was unexpected. A study conducted by de Wijk et al. (2012), showed significantly

428 higher facial expression responses upon seeing and tasting disliked foods when compared to

429 liked foods. Results suggesting negative emotions are more intensely expressed with disliked

430 samples, while samples falling somewhere between neutral and positive on the liking scale are

431 more likely to elicit smaller degrees of positive emotion; these findings were supported by

432 previous work of Danner et al. (2013), Danner et al. (2014), Wendin, Allesen-Holm, \& Bredie

433 (2011) and Zeinstra, Koelen, Colindrews, Kok, \& de Graaf (2009). These conclusions were not

434 fully supported by mean results from this study. It has also been suggested that happy is rarely

435 expressed through facial expressions outside of social settings (De Wijk, He, Mensink,

436 Verhoeven \& De Graaf, 2014; Parkinson, 2005).

437 One proposed explanation involving the low emotional mean intensity responses to sweet

438 taste in tea (and water) is that the inherent acceptance and habitual consumption of sweetened

439 products in general is related (Leterme, Brun, Dittmar, \& Robin, 2008). Other studies examining

440 ANS responses to basic tastes found that sucrose elicited weaker responses overall using the six

441 basic emotions compared to the other tastes and especially bitter (Robin, Rousmans, Dittmar, \&

442 Vernet-Maury, 2003; Rousmans, Robin, Dittmar, \& Vernet-Maury, 2000).

443 Another potential explanation for the lack of differences was the high variation in

444 emotional response across all panelists for one sweetener and within individual panelists across

445 all sweeteners. This variation could be due to differing responses from the reward system in the 
446 brain associated with sweetener consumption patterns across individuals as suggested by Green

447 \& Murphy (2012). Danner et al. (2013) attributed high variance in facial expressions to unnatural

448 laboratory settings. Environmental factors such as poor lighting conditions, unoptimized camera

449 angles and partial face occlusion may have contributed to poor video capture resulting in

450 response variation. Kotsia, Buciu \& Pitas (2008) found supporting evidence stating that partial

451 occlusion of the mouth especially affects the interpretation of anger and fear emotions, whereas

452 partial eye occlusion affected disgust and surprise.

453 Other studies have proposed using baseline measures such as water or neutral facial

454 expression (Garcia-Burgos \& Zamora, 2015) to eliminate individual biases. Calculated mean

455 intensity scores, using neutral as a correction factor against other emotions, showed lack of

456 robust differences across sweeteners in our study. Further exploration of panelist to panelist

457 facial expression variance is needed, although it has been suggested that neutral state may not be

458 the best measurement when making comparisons (Somerville, Kim, Johnstone, Alexander \&

459 Whalen, 2004).

460 Differences in expressed intensity and sequence of emotions across sweeteners in relation

461 to the $5 \mathrm{sec}$ post-consumption time period were observed when compared to a water baseline

462 (Figures 4, 5). Between 1 and $2.5 \mathrm{sec}$ post-consumption, there appeared to be significant

463 differences $(\mathrm{p}<0.05)$ in expressivity of disgust (withdrawal emotion) for the water-sucrose

464 (natural session) comparison and the water-honey comparison (Figure 4). Both sweeteners

465 (sucrose, honey) appeared to elicit less disgust than water, evidenced by the disgust curves

466 (Figures $4 \mathrm{~b}, 4 \mathrm{c}$ ) falling below the dotted significance line $(\mathrm{p}=0.05)$. Sucrose exposure appeared

467 to elicit a significantly higher amount of the negative emotion anger (as identified by AFEA)

468 than water for approximately $2 \mathrm{sec}$ post-consumption $(1.5-2.5 \mathrm{sec} ; 3.5-4 \mathrm{sec})$. The identification 
470 term. Further research will be needed to determine if this is an anomaly or a true emotional

471 response. No significant differences between HFCS and water were observed, although spikes in

472 two emotions (disgust \& sad) appeared at similar times in relation to trends for sucrose and

473 honey, suggesting similar emotion response within the sweetener category (Figure 4). Similar to

474 findings in the verbal questionnaire, natural sweeteners elicited less emotions and at lower

475 intensities over the set time period than sweeteners in the artificial category.

476 Three approach emotions (angry, happy and surprised) stood out as having observed

477 intensity and time differences $(\mathrm{p}<0.05)$ across all artificial sweetener-water comparisons (Figure

478 5). Expression of surprised had the highest intensity with apparent significance beginning around

4791 second post-consumption for all three; however, differences exist across sweeteners when

480 interpreting elicited surprise in comparison to water. Sucrose exposure appeared to elicit less

481 surprise in general than water, but especially so between 1.5 and 3.5 sec post-consumption

482 (Figure 5). Both alternative sweeteners appeared to elicit more surprise than water, but at

483 different time frames; significance for ace-k occurred around 1 second post-consumption,

484 whereas significance for sucralose occurred between 2 and 3 sec post-consumption (Figure 5).

485 Sequencing for elicitation of happy were similar for sucrose and ace-K, occurring around 3-4 sec

486 post-consumption, whereas sucralose elicited happy within the first second (Figure 5). Anger

487 was elicited at differing times across sweeteners and at minimal intensities.

488 Overall, significant differences $(\mathrm{p}<0.05)$ for expressed approach emotions only occurred

489 when comparing artificial sweeteners (and sucrose) to water, which we used as our control

490 (Figure 5); significance for expressed withdrawal emotions only occurred when comparing

491 sweeteners from the natural category to water (Figure 4). It is important to reiterate that 
492 participant variance was very high. Spikes indicating significance were most likely due to false

493 positives or major changes (drops/additions) in participant number due to sample pooling. The

494 time series method of analysis has the potential to benefit interpretations of micro emotions

495 elicited from food by adding the additional piece of information regarding time to baseline 496 comparisons; however, over interpreting the results is a risk.

\section{Conclusions}

The focus of this study was to explore whether differences in expressed emotions

501 (implicit and explicit) exist among similar products and whether they are related to overall

502 liking. Results showed that more emotions (and the intensity of each) were expressed by

503 panelists due to artificial sweeteners than natural sweeteners, regardless of overall liking or the

504 explicit/implicit tool utilized. Differentiation in liked versus disliked sweeteners (within

505 categories) was found when using verbal responses but not facial expressions. While self-report

506 emotion term questionnaires have begun to aid companies in understanding consumer

507 acceptability and associated emotions, it is believed that facial expression analysis may aid in

508 finding rapid, uncontrollable micro emotion responses that influence liking and preferences.

509 Limitations still exist in regards to panelist variation and AFEA software sensitivity

510 during video capture; optimization of environmental settings is key. Exploring emotion patterns

511 elicited by varying stimuli over time may provide additional value in understanding

512 uncontrollable micro emotions in relation to verbal expressions of emotion and acceptability.

513 Future research in the area of automated facial expression analysis should focus on finding subtle 
514 differences in emotion expression by product users and how/if those differences are related to

515 product successes rather than failures in the marketplace.

516

517

518

519

520

521

522

523

524

525

526

527

528

529

530

531

532

533

534

535

536

537

538

539

540

541

542

543

544

545

546

547

\section{Acknowledgments}

This project was funded, in part, by ConAgra Foods, Omaha, NE, U.S.A. Funding for this work was provided in part by the Virginia Agricultural Experiment Station and the Hatch Program of the National Institute of Food and Agriculture, U.S. Department of Agriculture. Special thanks go to Dr. Julie Dunsmore for her contributions and support of this project as well as the Water Interdisciplinary Graduate Education Program (IGEP). We also acknowledge the contribution of sweeteners by Wego Chemical \& Mineral Co., Tate \& Lyle and Big Tree Farms.

\section{References}

Alves, N.T., Fukusima, S.S. \& Aznar-Casanova, J.A. (2008). Models of brain asymmetry in emotional processing. Psychology \& Neuroscience, 1(1), 63-66.

Arnade, E.A. (2013). Measuring consumer emotional response to tastes and foods through facial expression analysis. Master's Thesis (Major Professor: S.E. Duncan), Virginia Polytechnic Institute and State University, Blacksburg, VA.

Balentine, D.A., Wiseman, S.A. \& Bouwens, L.C.M. (1997). The chemistry of tea flavonoids. Critical Reviews in Food Science and Nutrition, 37(8), 693-704.

Birch, G.G. (1987). Sweetness and sweeteners. Endeavour, 11(1), 21-24.

Booth, D.A. (1994). Psychology of Nutrition. Bristol, PA: Taylor and Francis.

Cardello, A.V. (1994). Consumer expectations and their role in food acceptance. In

Measurement of Food Preferences. (pp. 253-297). Springer, U.S.

Cogent Research, LLC (Cambridge, MA). 2006. High fructose corn syrup: consumer communications. Report and at-a-glance executive summary. Washington (DC): International Food Information Council (IFIC). 
Danner, L., Haindl, S., Joechl, M., \& Duerrschmid, K. (2014). Facial expressions and autonomous nervous system responses elicited by tasting different juices. Food Research International, 64(2014), 81-90.

Danner, L., Sidorkina, L., Joechl, M., \& Duerrschmid, K. (2013). Make a face! Implicit and explicit measurement of facial expressions elicited by orange juices using face reading technology. Food Quality and Preference, 32(Part B), 167-172.

Davidson, R.J., Ekman, P., Saron, C.D., Senulis, J.A., \& Friesen, W.V. (1990). Approachwithdrawal and cerebral asymmetry: emotional expression and brain physiology I. Journal of Personality and Social Psychology, 58(2), 330-341.

De Graaf, C. \& Zandstra, E.H. (1999). Sweetness intensity and pleasantness in children, adolescents, and adults. Physiology \& Behavior, 67(4), 513-520.

De Wijk, R. A., He, W., Mensink, M. G., Verhoeven, R. H., \& de Graaf, C. (2014). ANS responses and facial expressions differentiate between the taste of commercial breakfast drinks. Plos One, 9(4), e93823.

De Wijk, R.A., Kooijman, V., Verhoeven, R.H.G., Holthuysen, N.T.E., \& de Graaf, C. (2012). Autonomic nervous system responses on and facial expressions to the sight, smell and taste of liked and disliked foods. Food Quality and Preference, 26(2), 196-203.

Desmet, P.M.A., \& Schifferstein, H.N.J. (2008). Sources of positive and negative emotions in food experience. Appetite, 50(2-3), 290-301.

Devcich, D.A., Pedersen, I.K., \& Petrie, K.J. (2007). You eat what you are: Modern health worries and the acceptance of natural and synthetic additives in functional foods. Appetite, 48(3), 333-337.

Dickson-Spillmann, M., Siegrist, M., \& Keller, C. (2011). Attitudes toward chemicals are associated with preference for natural food. Food Quality \& Preference, 22(1), 149-156.

Ekman, P., \& Friesen, W.V. (1978). Facial Action Coding System: A Technique for the Measurement of Facial Movement. Palo Alto, CA: Consulting Psychologists Press.

Ekman, P., Friesen, W.V., \& Ancoli, S. (1980). Facial signs of emotional experience. Journal of Personality \& Social Psychology, 39(6), 1125-1134.

Fischer, R., Griffin, F., England, S., \& Garn, S.M. (1961). Taste thresholds and food dislikes. Nature, 191, 1328.

Frank, G. K., Oberndorfer, T. A., Simmons, A. N., Paulus, M. P., Fudge, J. L., Yang, T. T., \& Kaye, W. H. (2008). Sucrose activates human taste pathways differently from artificial sweetener. Neuroimage, 39(4), 1559-1569. 
594

Garcia-Burgos, D., \& Zamora, M.C. (2015). Exploring the hedonic and incentive properties in preferences for bitter foods via self-reports, facial expressions and instrumental behaviours. Food Quality and Preference, 39, 73-81.

Gendron, M., Lindquist, K. A., Barsalou, L., \& Barrett, L. F. (2012). Emotion words shape emotion percepts. Emotion, 12(2), 314.

Gibson, E.L. (2006). Emotional influences on food choice: sensory, physiological and psychological pathways. Physiology and Behavior, 89(1), 53-61.

Green, E., \& Murphy, C. (2012). Altered processing of sweet taste in the brain of diet soda drinkers. Physiology \& Behavior, 107(4), 560-567.

Greimel, E., Machts, M., Krumhuber, E., \& Ellgring, H. (2006). Facial and affective reactions to tastes and their modulation by sadness and joy. Physiology \& Behavior, 89 (2), 261-269.

Hedrick, V.E., Comber, D.L., Estabrooks, P.A., Savla, J., \& Davy, B.M. (2010). The beverage intake questionnaire: determining initial validity and reliability. American Dietetic Association, $110(8), 1227-1232$.

Hu, S., Player, K.A., McChesney, K.A., Dalistan, M.D., Tyner, C.A. \& Scozzafava, J.E. (1999). Facial EMG as an indicator of palatability in humans. Physiology and Behavior, 68(1-2), 31-35.

International Food Information Council Foundation (IFIC). (May 2013). [Survey of consumer attitudes toward food safety, nutrition \& health]. Retrieved September 26, 2014, from the International Food Information Council Foundation website: http://www.foodinsight.org/articles/2013-food-and-health-survey.

King, S.C. \& Meiselman, H.L. (2010). Development of a method to measure consumer emotions associated with foods. Food Quality and Preference, 21(2), 168-177.

King, S.C., Meiselman, H.L., \& Carr, B.T. (2013). Measuring emotions associated with foods: Important elements of questionnaires and test design. Food Quality and Preference, 28(1), 8-16.

Kohler, C.G., Turner, T., Stolar, N.M., Bilker, W.B., Brensinger, C.M., Gur, R.E., Gur, R.C. (2004). Differences in facial expressions of four universal emotions. Psychiatry Research, $128(3), 235-244$.

Köster, E.P. (2002). The psychology of food choice: some often encountered fallacies. Food Quality and Preference, 14(5-6), 359-373.

Kotsia, I., Buciu, I., \& Pitas, I. (2008). An analysis of facial expression recognition under partial facial image occlusion. Image and Vision Computing, 26(7), 1052-1067. 
Leterme, A., Brun, L., Dittmar, A., \& Robin, O. (2008). Autonomic nervous system responses to sweet taste: evidence for habituation rather than pleasure. Physiology \& Behavior, 93(4-5), 994-

Li, X., Inoue, M., Reed, D.R., Huque, T., Puchalski, R.B., Tordoff, M.G., Ninomiya, Y., Beauchamp, G.K., \& Bachmanov, A.A. (2001). High-resolution genetic mapping of the saccharin preference locus (Sac) and the putative sweet taste receptor (T1R1) gene (Gpr70) to mouse distal Chromosome 4. Mammalian Genome, 12(1), 13-16.

Li, X., Staszewski, L., Xu, H., Durick, K., Zoller, M., \& Adler, E. (2002). Human receptors for sweet and umami taste. Proceedings of the National Academy of Sciences of the United States of America, 99(7), 4692-4696.

Lindquist, K. A., Barrett, L. F., Bliss-Moreau, E., \& Russell, J. A. (2006). Language and the perception of emotion. Emotion, 6(1), 125.

Lindstrom, M. (2005). Brand Sense: Build Powerful Brands Through Touch, Taste, Smell, Sight and Sound. New York, NY: Free Press.

Meyners, M., Castura, J. C., \& Carr, B. T. (2013). Existing and new approaches for the analysis of CATA data. Food Quality and Preference, 30(2), 309-319.

Mitchell, H. (2006). Sweeteners and Sugar Alternatives in Food Technology. Oxford: Blackwell Publishing Ltd.

Nabors, L.O. (2012). Alternative Sweeteners. ( $4^{\text {th }}$ ed.). Boca Raton, FL: Taylor \& Francis Group, LLC.

Nelson, G., Hoon, M. A., Chandrashekar, J., Zhang, Y., Ryba, N. J., \& Zuker, C. S. (2001). Mammalian sweet taste receptors. Cell, 106(3), 381-390.

Nie, Y., Vigues, S., Hobbs, J. R., Conn, G. L., \& Munger, S. D. (2005). Distinct contributions of T1R2 and T1R3 taste receptor subunits to the detection of sweet stimuli. Current Biology, 15(21), 1948-1952.

Noldus Information Technology (2012). FaceReader 5.0 ${ }^{T M}$ Reference Manual. Noldus Information Technology, Wageningen, The Netherlands. Available from http://www.noldus.com. Last accessed October 28, 2014.

Parkinson, B. (2005). Do facial movements express emotions or communicate motives? Personality and Social Psychology Review, 9(4), 278-311.

Porcherot, C., Delplanque, S., Raviot-Derrien, S., Le Calve, B., Chrea, C., Gaudreau, N., \& Cayeux, I. (2010). How do you feel when you smell this? Optimization of a verbal measurement of odor-elicited emotions. Food Quality and Preference, 21(8), 938-947. 
R Core Team (2014). R: A language and environment for statistical computing. R Foundation for Statistical Computing, Vienna, Austria. URL http://www.R-project.org/.

Robbins, S.P., \& Judge, T.A. (2013). Emotions and moods. In Essentials of Organizational Behavior (pp. 258-297). Upper Saddle River, NJ: Prentice Hall.

Robin, O., Rousmans, S., Dittmar, A., \& Vernet-Maury, E. (2003). Gender influence on emotional responses to primary tastes. Physiology \& Behavior, 78(3), 385-393.

Rousmans, S., Robin, O., Dittmar, A., \& Vernet-Maury, E. (2000). Autonomic nervous system responses associated with primary tastes. Chemical Senses, 25(6), 709-718.

Rozin, P., Ashmore, M., \& Markwith, M. (1996). Lay American conceptions of nutrition: dose insensitivity, categorical thinking, contagion, and the monotonic mind. Health Psychology, 15(6), 438-447.

Rozin, P., Spranca, M., Krieger, Z., Neuhaus, R., Surillo, D., Swerdlin, A., \& Wood, K. (2004). Preference for natural: instrumental and ideational/moral motivations, and the contrast between foods and medicines. Appetite, 43(2), 147-154.

Rozin, P. \& Vollmecke, T.A. (1986). Food likes and dislikes. Annual Review of Nutrition 6, 433456.

Schifferstein, H.N.J., Fenko, A., Desmet, P.M.A., Labbe, D., Martin, N. (2013). Influence of package design on the dynamics of multisensory and emotional food experience. Food Quality and Preference, 27 (1), 18-25.

Somerville, L.H., Kim, H., Johnstone, T., Alexander, A.L., \& Whalen, P.J. (2004). Human amygdala responses during presentation of happy and neutral faces: correlations with state anxiety. Biological Psychiatry, 55(9), 897-903.

Southern Sweet Tea. (n.d.). Retrieved April 30, 2013, from Lipton Tea website: http://www.liptontea.com/recipes/.

Spivey, M.J., Grosjean, M., \& Knoblich, G. (2005). Continuous attraction toward phonological competitors. Proceedings of the National Academy of Sciences (PNAS), 102(29), 10393-10398.

Steiner, J.E. (1979). Human facial expressions in response to taste and smell stimulation. Advances in Child Development and Behavior, 22, 257-295.

Steiner, J.E., Glaser, D., Hawilo, M.E., \& Berridge, K.C. (2001). Comparative expression of hedonic impact: affective reactions to taste by human infants and other primates. Neuroscience and Biobehavioral Reviews, 25(1), 53-74. 
729 Wendin, K., Allesen-Holm, B.H., \& Bredie, W.L.P. (2011). Do facial reactions add new

730 dimensions to measuring sensory responses to basic tastes? Food Quality and Preference, 22(4), 731 346-354.

732

733

734

735

White Jr, J.W. (1978). Honey. Advances in Food Research, 24, 287-374.

736

737

738

739

740

741

742

743

Whorf, B.L. (1956). Language, Thought and Reality. Cambridge, MA: Technology Press of Massachusetts Institute of Technology.

Zajonc, R.B. (1980). Feeling and thinking. Preferences need no inferences. American

Psychologist, 35 (2), 151-175.

Zeinstra, G.G., Koelen, M.A., Colindrews, D., Kok, F.J., \& de Graaf, C. (2009). Facial

expressions in school-aged children are a good indicator of "dislikes", but not of "likes". Food Quality and Preference, 20(8), 620-624. 
746 Table 1. Final alternative sweetener concentrations established to be sucrose-equivalent

\begin{tabular}{lll}
\hline Category & Sweetener & Concentration $(\mathrm{g} / \mathrm{mL})$ \\
\hline Control & Sucrose & 0.05 \\
Natural sweeteners & HFCS & 0.085 \\
& Honey & 0.062 \\
Artificial sweeteners & Ace-K & $2.6 \times 10^{-4}$ \\
& Sucralose & $9.5 \times 10^{-5}$ \\
\hline
\end{tabular}


751 Table 2. Mean hedonic scores ${ }^{1}$ for natural and artificial sweeteners in cold tea

Natural Session

\begin{tabular}{ccccccccc}
\multicolumn{9}{c}{ FER $^{\mathbf{2}}$} \\
\hline Sweetener & Mean & SD & $95 \%$ CI & Median & Mean & SD & $95 \%$ CI & Median \\
Sucrose & $6.7^{\text {aA }}$ & 1.2 & $6.3-7.2$ & 7.0 & $6.4^{\mathrm{aA}}$ & 1.4 & $5.9-6.9$ & 7.0 \\
HFCS & $6.5^{\mathrm{aA}}$ & 1.1 & $6.1-6.9$ & 6.0 & $6.1^{\mathrm{aA}}$ & 1.4 & $5.6-6.6$ & 6.0 \\
Honey & $5.5^{\mathrm{bA}}$ & 1.6 & $4.9-6.1$ & 5.5 & $4.7^{\mathrm{bA}}$ & 1.6 & $4.1-5.3$ & 4.0
\end{tabular}

\section{Artificial Session}

\begin{tabular}{ccccccccc}
\hline Sweetener & Mean & SD & $95 \%$ CI & Median & Mean & SD & $95 \%$ CI & Median \\
Sucrose $^{\mathbf{3}}$ & $6.8^{\mathrm{aA}}$ & 1.3 & $6.3-7.3$ & 7.0 & $6.6^{\mathrm{aA}}$ & 1.4 & $6.1-7.1$ & 7.0 \\
Ace-K $^{\mathrm{bA}}$ & $5.9^{\mathrm{BA}}$ & 1.3 & $5.4-6.4$ & 6.0 & $5.3^{\mathrm{bA}}$ & 1.9 & $4.6-6.0$ & 6.0 \\
Sucralose & $6.5^{\mathrm{abA}}$ & 1.6 & $5.9-7.1$ & 7.0 & $6.3^{\mathrm{aA}}$ & 1.7 & $5.7-6.9$ & 7.0 \\
\hline
\end{tabular}

752

a, b, c Means in each sweetener row and session category column (natural; artificial) with different

753 letters are significantly different across treatments at $\mathrm{p}<0.05$.

$754 \quad$ A,B Means in each sweetener row with different letters are significantly different within

755 treatments at $\mathrm{p}<0.05$.

$756{ }^{1} \mathrm{n}=30 ; 1=$ extremely dislike; $9=$ extremely like.

$757{ }^{2}$ Sessions: FER= Facial expression response session; ETS= Emotional term selection session.

$758{ }^{3}$ Artificial sweetener session included sucrose as the standard control.

759

760 
762 Table 3. Mean emotional intensity values ${ }^{1}$ within water (baseline) and natural sweeteners ${ }^{2}$ in 763 cold tea

\begin{tabular}{crccc}
\hline Emotion & Water & Sucrose & HFCS & Honey \\
\hline Neutral & $0.555^{\mathrm{aA}}$ & $0.553^{\mathrm{aA}}$ & $0.546^{\mathrm{aA}}$ & $0.557^{\mathrm{aA}}$ \\
Sad & $0.176^{\mathrm{bA}}$ & $0.174^{\mathrm{bA}}$ & $0.166^{\mathrm{bA}}$ & $0.176^{\mathrm{bA}}$ \\
Surprised & $0.057^{\mathrm{cA}}$ & $0.063^{\mathrm{cA}}$ & $0.069^{\mathrm{bcA}}$ & $0.049^{\mathrm{cA}}$ \\
Happy & $0.026^{\mathrm{cA}}$ & $0.027^{\mathrm{cA}}$ & $0.030^{\mathrm{cA}}$ & $0.049^{\mathrm{cA}}$ \\
Scared & $0.028^{\mathrm{cA}}$ & $0.018^{\mathrm{cA}}$ & $0.021^{\mathrm{cA}}$ & $0.011^{\mathrm{cA}}$ \\
Angry & $0.006^{\mathrm{cA}}$ & $0.009^{\mathrm{cA}}$ & $0.008^{\mathrm{cA}}$ & $0.007^{\mathrm{cA}}$ \\
Disgusted & $0.001^{\mathrm{cA}}$ & $0.001^{\mathrm{cA}}$ & $0.005^{\mathrm{cA}}$ & $0.003^{\mathrm{cA}}$ \\
\hline
\end{tabular}

$764 \quad \mathrm{a}, \mathrm{b}, \mathrm{c}$ Means within each column with different letters are significantly different at $\mathrm{p}<0.05$.

$765{ }^{1}(\mathrm{n}=30)$; Mean intensity values $(0-1 ; 0=$ not expressed; $1=$ fully expressed) based on 5 second 766 video analysis of facial response (FaceReader 5.0, Noldus Information Technology,

767 Wageningen, The Netherlands) post-consumption of each sample on testing "Day 1" session.

$768{ }^{2}$ High fructose corn syrup (HFCS) and honey were added at equi-sweet concentration to 5\%

769 sucrose $(\mathrm{w} / \mathrm{w})$.

770

771 
773 Table 4. Mean emotional intensity values ${ }^{1}$ within water, sucrose, and artificial sweeteners ${ }^{2}$ in 774 cold tea

\begin{tabular}{ccccc}
\hline Emotion & Water & Sucrose & Ace-K & \multicolumn{1}{c}{ Sucralose } \\
\hline Neutral & $0.568^{\mathrm{aA}}$ & $0.569^{\mathrm{aA}}$ & $0.599^{\mathrm{aA}}$ & $0.562^{\mathrm{aA}}$ \\
Sad & $0.138^{\mathrm{bA}}$ & $0.132^{\mathrm{bA}}$ & $0.106^{\mathrm{bA}}$ & $0.135^{\mathrm{bA}}$ \\
Surprised & $0.048^{\mathrm{bcA}}$ & $0.111^{\mathrm{bA}}$ & $0.083^{\mathrm{bcA}}$ & $0.100^{\mathrm{bcA}}$ \\
Happy & $0.057^{\mathrm{bcA}}$ & $0.040^{\mathrm{bcA}}$ & $0.061^{\mathrm{bcA}}$ & $0.046^{\mathrm{bcA}}$ \\
Scared & $0.045^{\mathrm{bcA}}$ & $0.020^{\mathrm{cA}}$ & $0.012^{\mathrm{cA}}$ & $0.034^{\mathrm{bcA}}$ \\
Angry & $0.003^{\mathrm{cA}}$ & $0.009^{\mathrm{cA}}$ & $0.010^{\mathrm{cA}}$ & $0.009^{\mathrm{cA}}$ \\
Disgusted & $0.002^{\mathrm{cA}}$ & $0.002^{\mathrm{cA}}$ & $0.005^{\mathrm{cA}}$ & $0.002^{\mathrm{cA}}$
\end{tabular}

a, b, c, d Means within each column with different letters are significantly different at $\mathrm{p}<0.05$. video analysis of facial response (FaceReader 5.0, Noldus Information Technology, Wageningen, The Netherlands) post-consumption of each sample on testing "Day 2" session. 
List of Figures.

Figure 1. Cross-over experimental design. Videos of implicit facial expression response data were captured immediately after consumption and prior to explicit hedonic score data in FER

800 session; as such, the first task panelists were asked to complete was the hedonic score for each sweetener upon consumption in both sessions.

Figure 2. Comparison of frequently selected emotion terms from emotion term selection sessions for sweeteners in cold tea; (a) sucrose in natural and artificial sessions; (b) natural session; (c) artificial session. $(n=30)$ The displayed emotion terms $(23 / 43)$ were selected based on a $20 \%$ or greater selection frequency for at least one of the samples being compared. Terms were ordered clockwise alphabetically. Shared terms, having $20 \%$ or greater frequency among samples and a

Figure 3. Penalty-lift analysis for natural \& artificial sweeteners in cold tea $(n=62$ total observations; $n=31$ for natural sweeteners; $n=31$ for artificial sweeteners). Differences in mean acceptability scores for all sample conditions were found for the 'frequently selected' terms ( $>20 \%$ selection; natural: 18 terms; artificial: 17 terms) and between participants who selected and did not select the term.

Figure 4. Time series analysis (5 seconds) of emotions from facial expression analysis session, comparing natural sweeteners to water baseline. Emotions with extended duration below the dotted line $(\mathrm{p}<0.05)$ are different from emotions elicited by water. (a) high fructose corn syrup; (b) honey; (c) sucrose.

Figure 5. Time series analysis (5 seconds) of emotions from facial expression analysis session, comparing sucrose (control) and artificial sweeteners in cold tea to water baseline. Emotions with extended duration below the dotted line $(\mathrm{p}<0.05)$ are different from emotions elicited by water. (a) acesulfame k (Ace-K); (b) sucralose (SL); (c) sucrose (S);. 


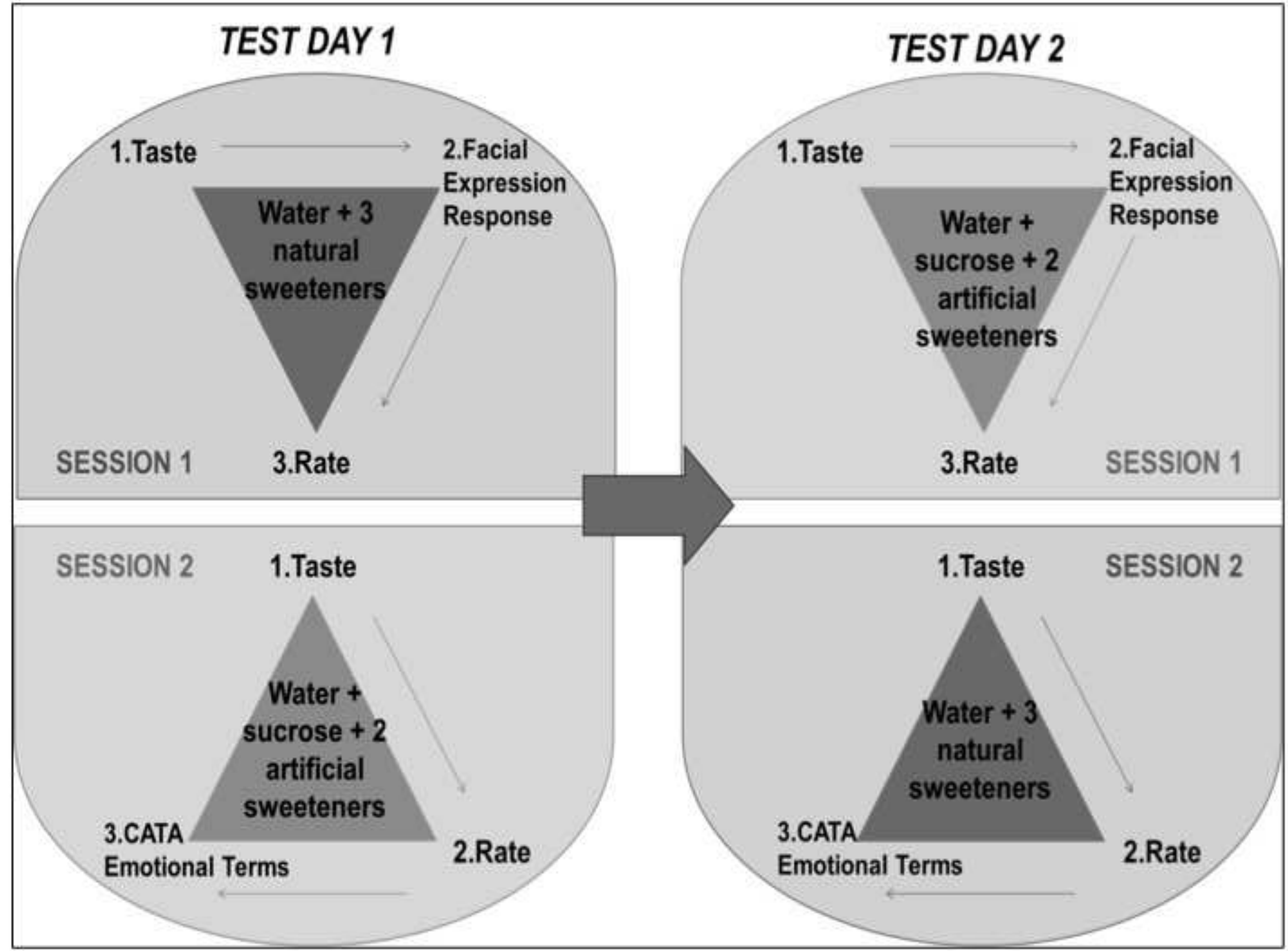


Click here to download high resolution image

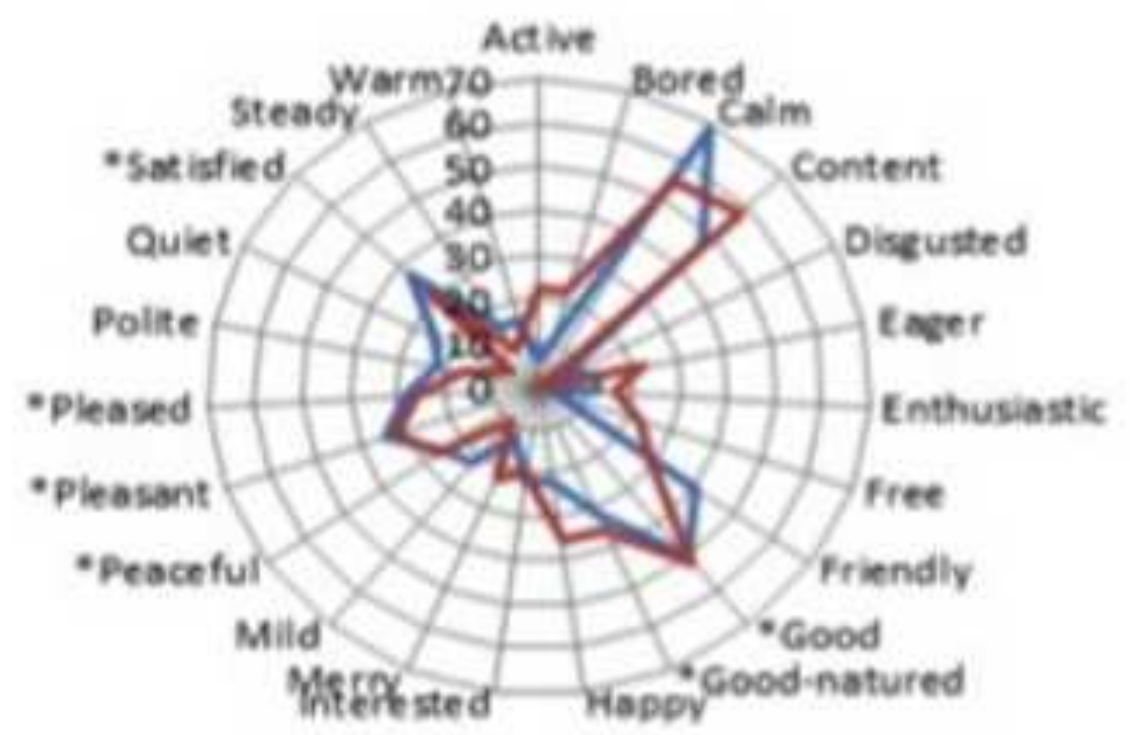

\section{-Anticial \\ Notural}
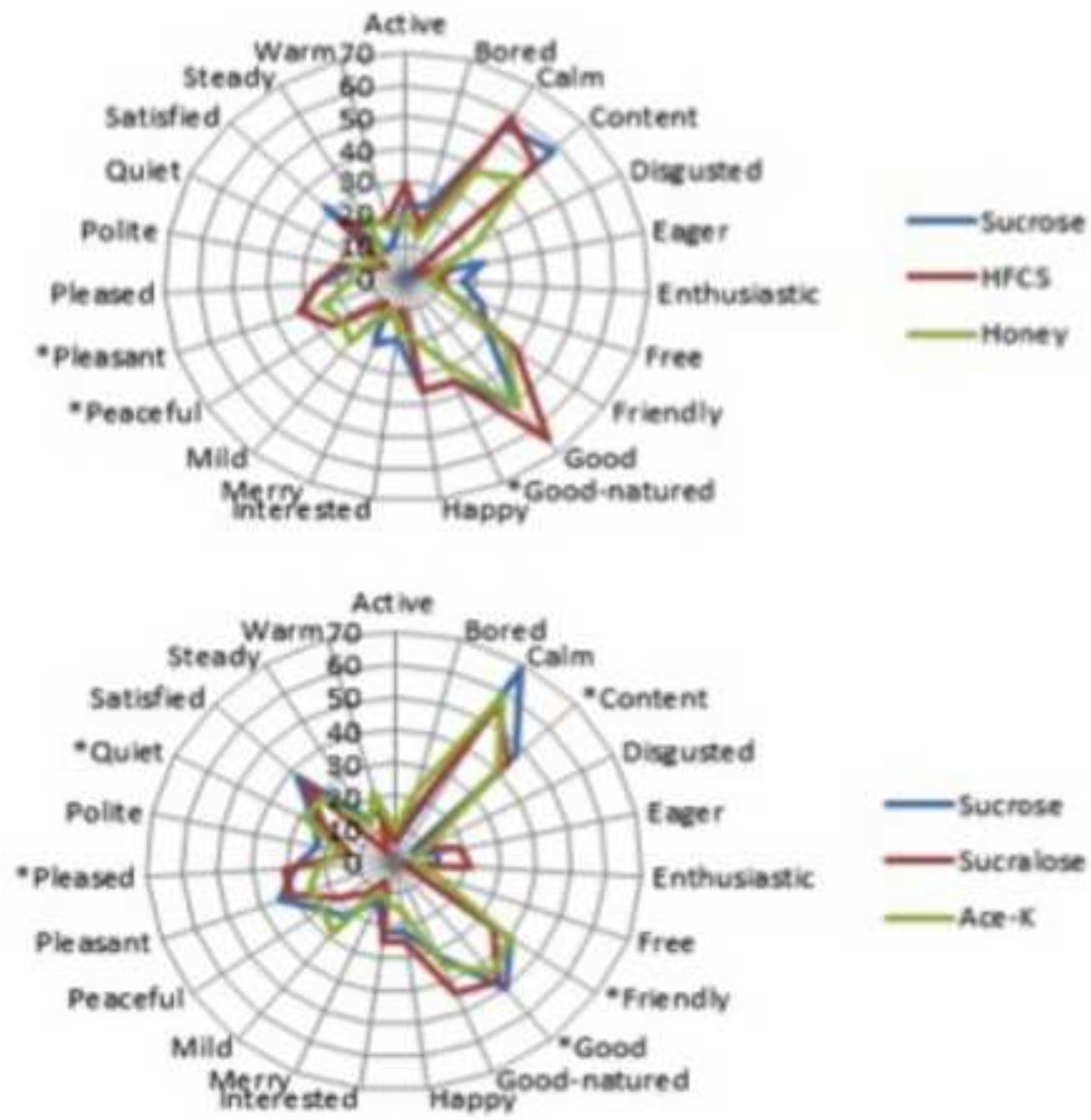

- Sucrose

- Sucralose

Ace- $\mathbf{K}$ 


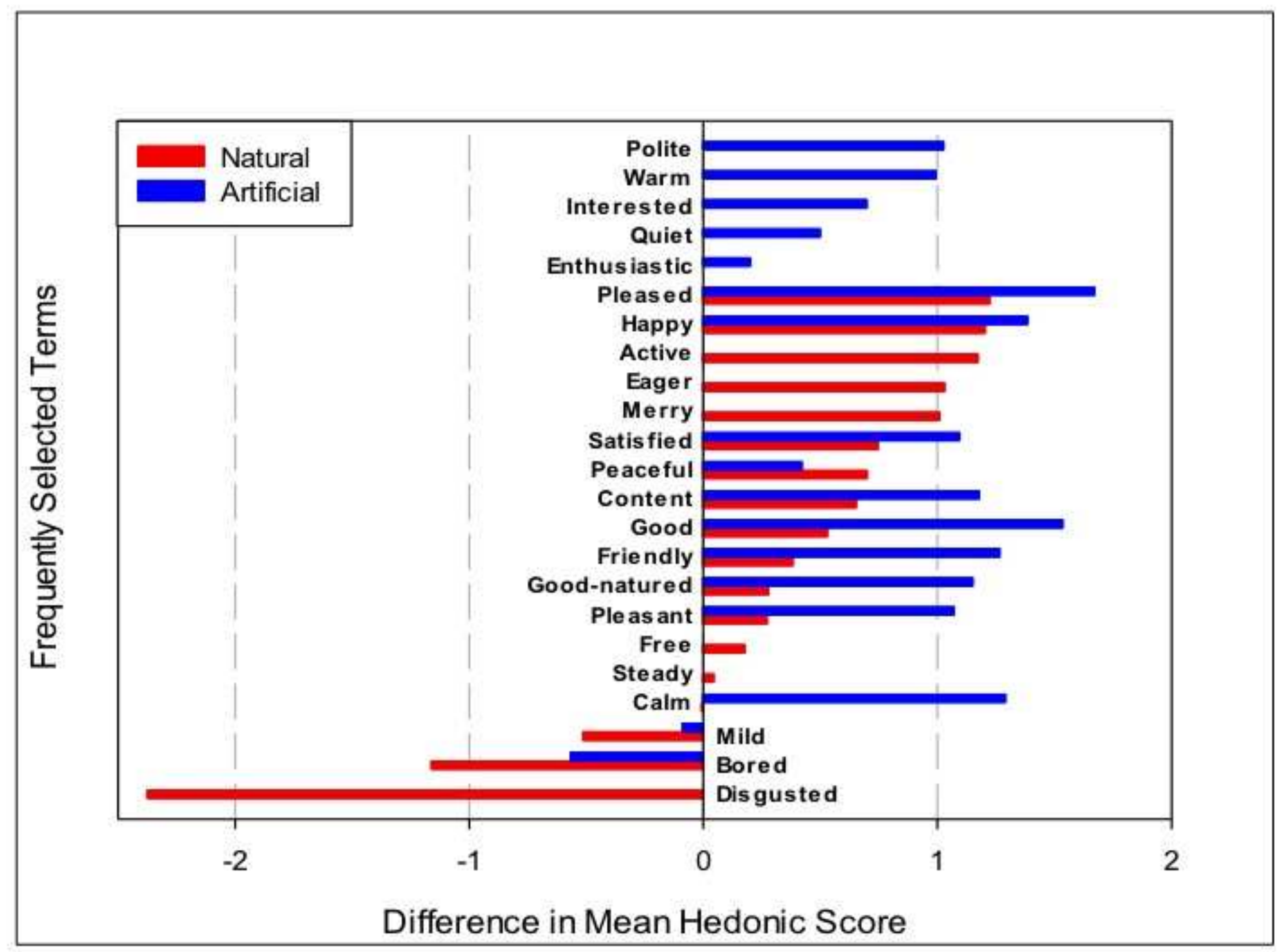


Click here to download high resolution image

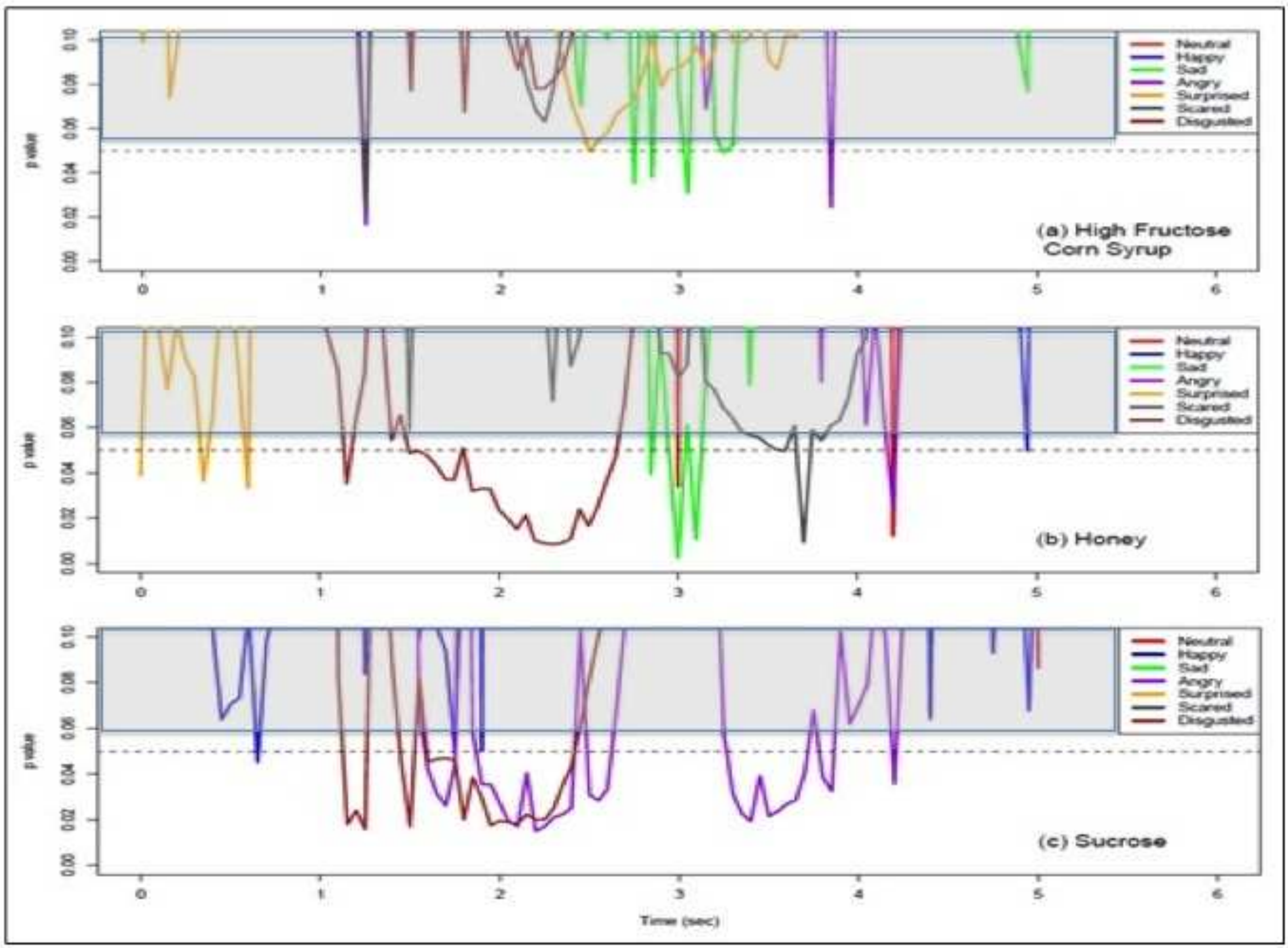


Click here to download high resolution image
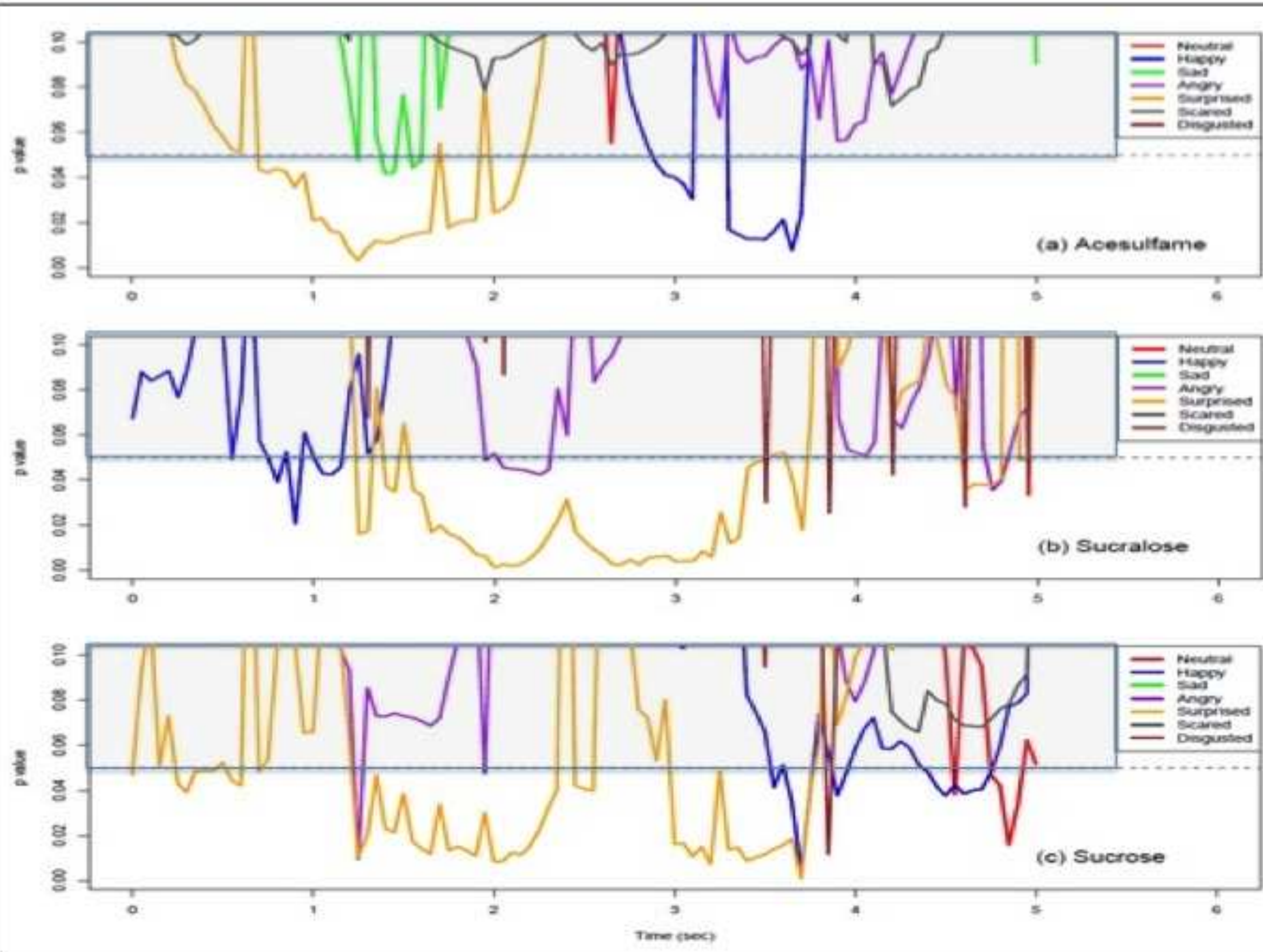